\section{Investigação de surto de sarampo no Estado do Pará na era da eliminação da doença no Brasil}

\author{
Investigation of a measles outbreak in Pará State, \\ Brazil, in the age of elimination of the disease
}

\author{
Investigación de brote de sarampión en el Estado \\ do Pará en la era de la eliminación de la \\ enfermedad en Brasil
}

\author{
1 Secretaria Municipal de \\ Saúde de Salvador, Salvador, \\ Brasil. \\ 2 Secretaria de Vigilância em \\ Saúde, Ministério da Saúde, \\ Brasília, Brasil. \\ Correspondência \\ H. S. Jesus \\ Av. Mário Leal Ferreira 381 \\ apto. 1203, Salvador, BA \\ 40285-600, Brasil. \\ hianesj@hotmail.com
}

\begin{abstract}
In July 27th, 2010, witnessed the late notification of a positive test result for measles IgM antibodies in Belém, Pará State, Brazil, sparking an epidemiological investigation and control and preventive measures. Two more confirmed cases were identified, both of whom were siblings of the index case, with clinical signs and symptoms and incubation period consistent with measles. We conducted a retrospective search in hospitals and laboratories for suspected cases that lived in or had visited Pará State from May 1st to August 4th, 2010, and had presented fever and exanthema accompanied by cough and/ or sneezing and/or conjunctivitis. All identified cases were investigated by telephone contact and/or home visits. We reviewed 183,854 consultation forms and identified 56 (0.03\%) suspected cases. We applied 2,535 doses of triple viral vaccine distributed between blockades vaccination intensifications. A household measles outbreak occurred in Belém with the detection and isolation of a viral genotype imported from Europe. Timely and sensitive epidemiological surveillance is recommended for the detection of suspected cases of measles and maintenance of high immunization coverage.
\end{abstract}

Measles; Disease Outbreaks; Immunization; Epidemiological Surveillance
Hiane Santos de Jesus 1

Gilmara Lima Nascimento 2

Fabiano Marques Rosa 2

Deise Aparecida dos Santos 2

\section{Resumo}

Em 27 de julho de 2010, houve a notificação tardia de um resultado de IgM reagente para sarampo em Belém, Pará, Brasil, que gerou uma investigação epidemiológica e medidas de controle e prevenção. Foram encontrados mais dois casos confirmados, irmãos do primeiro caso, com clínica e período de incubação compativel com sarampo. Realizamos busca retrospectiva em hospitais e laboratórios, cujo caso suspeito fora o residente ou visitante do Pará, que entre 1 o de maio de 2010 e 4 de agosto de 2010, tenha apresentado febre e exantema acompanhado de tosse elou coriza elou conjuntivite. Todos os casos identificados foram investigados via contato telefônico elou visitas domiciliares. Revisamos 183.854 fichas de atendimento, sendo identificados 56 (0,03\%) casos suspeitos. Aplicamos 2.535 doses de vacina tríplice viral distribuídas entre bloqueios e intensificações vacinais. Ocorreu um surto intradomiciliar de sarampo em Belém com detecção e isolamento de genótipo viral importado da Europa. Recomenda-se uma vigilância epidemiológica oportuna e sensível à detecção de casos suspeitos de sarampo e manutenção de coberturas vacinais altas.

Sarampo; Surtos de Doenças; Imunização; Vigilãncia Epidemiológica 


\section{Introdução}

O sarampo é uma doença infecciosa aguda, endêmica em algumas partes do mundo, porém, no Brasil, a transmissão autóctone foi interrompida em 2000 1,2. Portanto, a notificação em Belém, Pará, Brasil, de um caso suspeito de sarampo, com resultado IgM reagente através do método ELISA, foi um evento de elevada magnitude para saúde pública.

\section{Materiais e métodos}

A notificação desse caso de sarampo desencadeou uma investigação epidemiológica, com o propósito de confirmar a existência do surto, identificar genótipo do vírus circulante e recomendar medidas de controle e prevenção, que resultou nesse estudo descritivo.

Para coleta de dados, realizamos uma busca retrospectiva de casos por meio das seguintes fontes:

- Prontuários e fichas de atendimento de hospitais;

- Fichas de Notificação Individual (FNI) e de atendimento do Laboratório Central do Estado do Pará (Lacen-PA) e do Instituto Evandro Chagas (IEC);

- Banco de dados do Sistema de Informação de Agravos de Notificação (SINAN) do Ministério da Saúde;

- Boletim de Notificação Semanal (BNS) da Secretaria do Estado de Saúde Pública do Pará (SESPA).

O período da busca retrospectiva foi de 10 de maio de 2010 a 4 de agosto de 2010, pois apesar de a notificação ter ocorrido em 27 de julho, o início de sintomas do caso 1 foi 5 de julho.

A busca deu-se no hospital para doenças infecciosas da rede pública, localizado no mesmo bairro do caso 1; nas cinco maiores unidades privadas de Belém; e num hospital privado de Ananindeua, município da região metropolitana de Belém, por acreditarmos que as classes socioeconômicas mais altas apresentam risco de exposição ao vírus do sarampo durante viagens internacionais, além de serem verificadas menores coberturas vacinais ${ }^{3}$.

Foram utilizadas as seguintes definições de caso:

- Triado: todo paciente residente ou visitante do Estado do Pará, que entre 1o de maio de 2010 e 4 de agosto de 2010, independente da idade e da situação vacinal, tenha apresentado febre e exantema ou suspeita diagnóstica de dengue ou exantema súbito ou virose a esclarecer sem descrição dos sinais e sintomas apresentados;
- Suspeito: todo caso triado, acompanhado de tosse e/ou coriza e/ou conjuntivite;

- Confirmado: todo caso suspeito com sorologia (IgM) reagente ou identificação viral positiva ou soroconversão da IgG com clínica e/ ou epidemiologia compatível.

Os casos triados foram investigados por contato telefônico para levantamento de características demográficas, sinais e sintomas apresentados, situação vacinal quanto à dupla ou tríplice viral e exposição ao vírus do sarampo ou contato com caso suspeito de outra doença exantemática. Na impossibilidade desse contato, realizaram-se visitas domiciliares.

Não foram realizados contatos telefônicos com os casos triados do Lacen-PA e IEC, pois alíquotas das amostras do soro, colhidas oportunamente, estavam armazenadas e foram testadas para sarampo.

Houve investigação domiciliar dos casos suspeitos de sarampo com coleta de amostra sanguínea e realização de medidas de controle e prevenção. Essas amostras foram colhidas no primeiro contato, sendo consideradas oportunas quando coletadas entre o lo e o 28 o dias do aparecimento do exantema e a segunda coleta ocorria entre 20 a 25 dias após a data da primeira ${ }^{2}$.

As amostras foram encaminhadas ao LacenPA para testagem sorológica para sarampo e rubéola através da técnica ELISA ${ }^{2}$.

As amostras de secreção nasofaríngea e urina dos casos confirmados foram enviadas para o Lacen-PA e Fundação Oswaldo Cruz (Fiocruz) no Rio de Janeiro para identificação viral utilizando o método de reação em cadeia da polimerase (PCR).

\section{Resultados}

O primeiro caso notificado era estudante de Farmácia, sexo masculino, hígido, 18 anos, no dia 5 de julho de 2010 apresentou hipertermia acompanhada de tosse e coriza. Após avaliação médica suspeitou-se de infecção respiratória aguda sendo prescrito nimesulida $100 \mathrm{mg}$ e paracetamol 500mg.

Em 7 de julho de 2010, apresentou conjuntivite e exantema máculo-papular, que progrediu no sentido cefálo-caudal, sendo reavaliado por médico, cuja suspeição diagnóstica fora alergia medicamentosa.

Em 12 de julho, durante avaliação com alergologista, houve a suspeição de sarampo e solicitação de exames laboratoriais para confirmação do caso. A amostra sanguínea foi colhida após esse atendimento em laboratório da rede privada de Belém com resultado IgM reagente para 
sarampo. A notificação ocorreu em 27 de julho de 2010, quando o laboratório informou a confirmação do caso.

No período, o estudante encontrava-se em férias da faculdade e, após adoecimento, ficou em isolamento domiciliar. O caso nunca fizera uso de vacina, segundo genitores. Não há relatos de viagem para o exterior, contato com estrangeiros ou indivíduos que retornaram de viagem ao exterior, bem como contato com caso suspeito ou confirmado de sarampo.

Em 24 de julho de 2010, os irmãos gêmeos desse caso, denominados casos 2 e 3 respectivamente, 26 anos, sexo masculino, apresentaram febre $\left(38^{\circ}-40^{\circ} \mathrm{C}\right)$. Em 26 de julho, surgiu exantema máculo-papular com progressão descendente. A coleta de sangue para realização da sorologia destes ocorreu no dia 28 de julho durante investigação epidemiológica do caso 1 .

Os casos 2 e 3 são estudantes de áreas da saúde, sem história de vacinação prévia contra o sarampo. $\mathrm{O}$ caso 2 residia com o caso 1 e não apresentou nenhum outro sintoma; já o caso 3, residente em São Paulo, visitava a família e também apresentou tosse, coriza, conjuntivite e artralgia.

Não houve complicações nem necessidade de hospitalização de nenhum dos casos.

Os casos 1 e 3 foram confirmados por critério laboratorial com isolamento e identificação do genótipo viral D4. O caso 2 foi confirmado por vínculo clínico-epidemiológico; porém a titulação de IgG na sua amostra 1 foi de $3.074 \mathrm{UI} / \mathrm{mL}$, e na amostra 2, colhida em 18 de agosto, essa titulação atingiu $14.705 \mathrm{UI} / \mathrm{mL}$.

Além disso, foram revisados 183.854 prontuários e fichas de atendimento, resultando em 647 $(0,3 \%)$ casos triados, dos quais 633 (98\%) foram provenientes da rede privada dos municípios (Figura 1). Após investigação desses casos foram identificados 56 casos suspeitos $(0,03 \%)$ entre as semanas epidemiológicas 18 e 34 distribuídos pelo Estado do Pará (Figura 2).

Quanto aos critérios de descarte dos casos, 47 (84\%) foram através do resultado laboratorial IgM não reagente e nove (16\%) pelo critério clínico-epidemiológico devido à coleta de amostra clínica em período inoportuno.

Figura 1

Busca retrospectiva de casos de suspeitos de sarampo. Pará, Brasil, 1ㅇ de maio de 2010 a 4 de agosto de 2010.

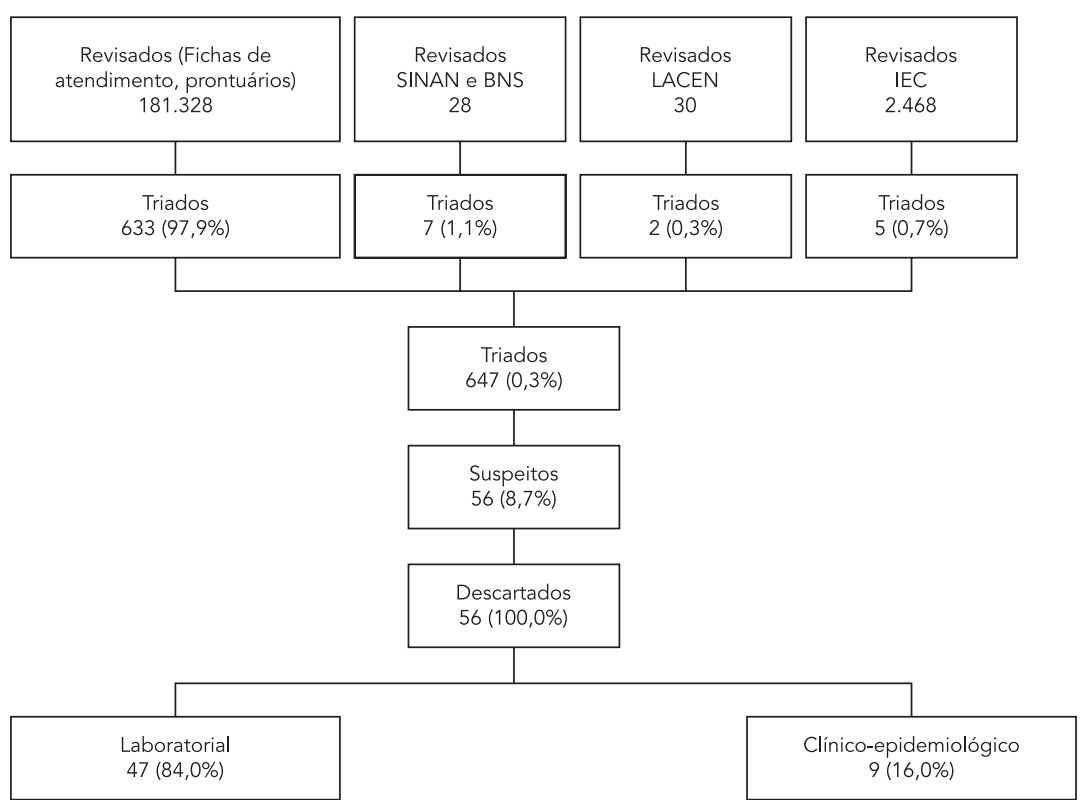

BNS: Boletim de Notificação Semanal (Secretaria do Estado de Saúde Pública do Pará - SESPA); IEC: Instituto Evandro Chagas; Lacen-PA: Laboratório Central do Estado do Pará; SINAN: Sistema de Informação de Agravos de Notificação (Ministério da Saúde). 
Figura 2

Distribuição e classificação final dos casos suspeitos de sarampo por data de início do exantema no Estado do Pará, Brasil, 1ㅇ de maio de 2010 a 4 de agosto de 2010.

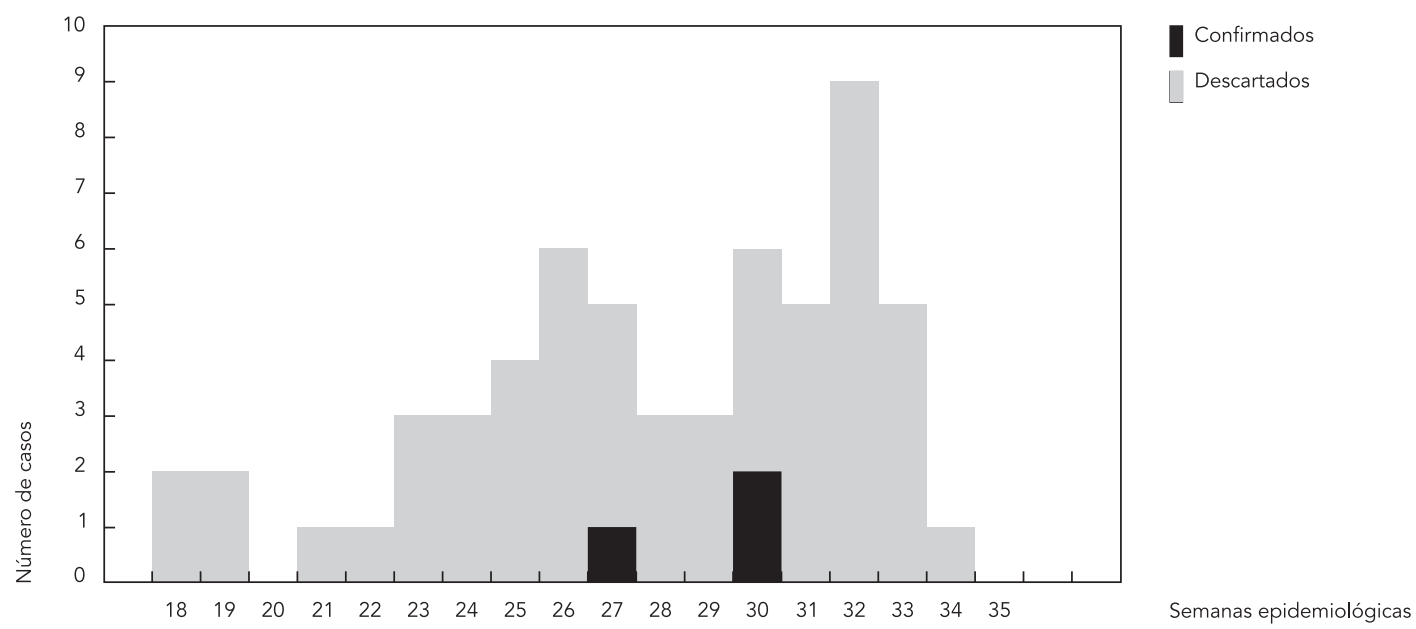

Essa situação gerou a aplicação de 2.535 doses de vacina tríplice viral distribuídas por quatro intensificações e 11 bloqueios vacinais realizados em Belém e Ananindeua entre 28 de julho e 27 agosto, correspondendo a uma taxa percentual de 0,27 dose aplicada por habitante.

Os bloqueios vacinais foram realizados nas áreas circunvizinhas ao domicílio dos casos suspeitos, na igreja frequentada pelos casos confirmados e intensificações vacinais nos postos de saúde que funcionavam até 22 horas e unidades de saúde com atendimento de urgência e emergência, ambas as modalidades de forma seletiva para indivíduos a partir de seis meses.

Para crianças e adolescentes de 4 a 19 anos de idade foram aplicadas $1.533(60 \%)$ doses de tríplice viral, das quais 421 (27\%) foram segunda dose. Entre os adultos aplicaram-se 898 (35\%) doses, sendo 10 (1\%) consideradas segunda dose.

Em 2008, na campanha indiscriminada com a vacina dupla viral para homens e mulheres de 20-39 anos, Belém atingiu uma cobertura vacinal de $98 \%$, além de coberturas de $104 \%$ em 2008 , $100 \%$ em 2009 e $109 \%$ em 2010 na vacinação de rotina com tríplice viral em população de um ano (Ministério da Saúde do Brasil. Sistema de informações do Programa Nacional de Imunizações. http://pni.datasus.gov.br, acessado em 30/ Mar/2011).

\section{Discussão e conclusão}

Ocorreu um surto de sarampo intradomiciliar em Belém, sustentado pela susceptibilidade dos casos, devido à opção por não vacinação dos mesmos. Foram detectados dois casos secundários envolvidos na mesma cadeia de transmissão, cujos períodos de incubação e transmissibilidade coincidem.

Essa situação aponta que a presença de bolsões de pessoas não vacinadas, seja esses provenientes de razões filosóficas ou falta de acesso a cuidados de saúde, pode sustentar a transmissão do sarampo 4 .

Não foi possível identificar a fonte primária de infecção. O genótipo viral D4 identificado refere-se aos surtos de sarampo ocorridos na Inglaterra, França, Itália e Holanda, cujo perfil genético difere dos demais genótipos registrados no Brasil.

A Organização Pan-Americana da Saúde (OPAS) e o Ministério da Saúde recomendam que indivíduos com doença exantemática febril e sorologia reagente para sarampo (IgM) sejam tratados como casos confirmados de sarampo, sendo necessário uma rápida implementação das estratégias de controle e prevenção como bloqueios e intensificações vacinais, investigação de contatos, busca retrospectiva e prospectiva de casos 1,2 .

O profissional de saúde, que suspeitou de sarampo e não notificou o caso, atrasou o início 
da investigação e a implementação de medidas de controle e prevenção, como ocorreu em outras investigações de casos importados de sarampo no país 3,5 .

Ressalta-se que as altas taxas de coberturas vacinais alcançadas em campanhas prévias ou na vacinação de rotina justifica a restrição do surto na região, cenário ratificado pelas baixas taxas de doses aplicadas, visto que os bloqueios e intensificações eram seletivos.

Algumas limitações foram destacadas, como viés de informação causado pela falta da descrição de sinais e sintomas em prontuários e fichas de atendimento e perda do cartão de vacinação, superestimando o número de primeiras doses;

\section{Resumen}

El 27 de julio de 2010 hubo una notificación tardía de un resultado de IgM reactivo al sarampión en Belém, Pará, Brasil, que generó una investigación epidemiológica y medidas de control y prevención. Se encontraron dos casos más confirmados, hermanos el primer caso, con clínica y período de incubación compatible con el sarampión. Realizamos una búsqueda retrospectiva en hospitales y laboratorios, cuyo caso sospechoso fuera el residente o visitante de Pará, que entre 1o de mayo de 2010 y el 4 de agosto de 2010, había presentado fiebre y exantema, seguido de tos y/o síntomas catarrales y/o conjuntivitis. Todos los casos identificados fueron investigados vía contacto telefónico y/o visitas domiciliarias. Revisamos 183.854 fichas de atención, siendo identificados 56 (0,03\%) casos sospechosos. Aplicamos 2.535 dosis de vacuna triple viral, distribuidas entre vacunas de bloqueo e intensificación. Se produjo un brote intradomiciliario de sarampión en Belém con detección y aislamiento del genotipo viral importado de Europa. Se recomienda una vigilancia epidemiológica oportuna y sensible a la detección de casos sospechosos de sarampión y mantenimiento de coberturas de vacunación altas.

Sarampión; Brotes de Enfermedades; Inmunización; Vigilancia Epidemiológica viés de seleção, pois endereços e telefones incorretos ou inexistentes impossibilitaram a localização dos casos triados e a escrita ilegível em prontuários e fichas de atendimento dificultaram a classificação adequada de casos suspeitos; viés de memória.

Diante do exposto, recomenda-se tornar a vigilância epidemiológica sensível e oportuna para detecção de casos suspeitos de sarampo, realizar busca ativa de casos suspeitos e/ou confirmados de sarampo em municípios e unidades silenciosas, sensibilizar profissionais de saúde da rede pública e privada quanto à obrigatoriedade da notificação imediata de sarampo.

\section{Colaboradores}

H. S. Jesus coordenou e participou da investigação no campo, responsável pela compilação e análise dos resultados, além da elaboração do manuscrito. G. L. Nascimento participou da investigação no campo e fez a revisão do manuscrito. F. M. Rosa coordenou a investigação no campo, auxiliou a organização da coleta dos dados e fez a revisão do manuscrito. D. A. Santos auxiliou na organização do trabalho de campo e na revisão do manuscrito.

\section{Agradecimentos}

Aos técnicos do Departamento de Epidemiologia (DEPI) da Secretaria de Estado de Saúde Pública do Pará (SESPA) e da Divisão de Vigilância Epidemiológica (DEVES) da Secretaria Municipal de Saúde e Meio ambiente de Belém (SESMA) que se dedicaram à investigação e contribuíram com seus conhecimentos e experiências. 


\section{Referências}

1. Pan American Health Organization. Measles elimination: field guide. $2^{\text {nd }}$ Ed. Washington DC: Pan American Health Organization; 2005. (Scientific and Technical Publication, 605).

2. Ministério da Saúde. Guia de vigilância epidemiológica da Secretaria de Vigilância em Saúde: sarampo. 7ạ Ed. Brasília: Ministério da Saúde; 2009.

3. Secretaria de Vigilância em Saúde, Ministério da Saúde. Casos importados de sarampo em Santa Catarina. http://portal.saude.gov.br/portal/svs/ visualizar_texto.cfm?idtxt=21287 (acessado em 21/ Jan/2011).
4. Domìnguez A, Torner N, Barrabeig I, Rovira A, Rius C, Cayla J, et al. Large outbreak of measles in a community with high vaccination coverage: implications for the vaccination schedule. Clin Infect Dis 2008; 47:1143-9.

5. Prevots DR, Parise MS, Segatto TCV, Siqueira MM, Santos ED, Ganter B, et al. Interruption of measles transmission in Brazil, 2000-2001. J Infect Dis 2003; 187 Suppl 1:S111-20.

Recebido em 06/Fev/2015

Versão final reapresentada em 19/Jun/2015

Aprovado em 09/Set/2015 